\title{
Diagnostic Value of Butanol Threshold Test in COVID-19 Related Olfactory Dysfunction
}

\author{
Akif İşlek ${ }^{1}$ (1) $\cdot$ Mustafa Koray Balcı $^{2}$ (B)
}

Received: 27 November 2020/Accepted: 25 January 2021/Published online: 6 February 2021

(C) Association of Otolaryngologists of India 2021

\begin{abstract}
Olfactory and taste dysfunction has been reported as a specific, preliminary symptom in COVID-19, but a few comparative studies with quantitative tests are reported. In this study, we aimed to compare the butanol olfactory threshold values between COVID-19 patients and healthy volunteers.A cross-sectional study was designed. A total of 53 patients were included in the COVID-19 group and the control group. The definitive diagnosis of COVID19 was made with reverse-transcription polymerase chain reaction (RT-PCR) test. Frequency of odor and taste dysfunction and other head and neck system-specific and other symptoms were recorded. Afterward, olfactory threshold values determined according to Connecticut Chemosensory Clinical Research Center (CCCRC) test principle for study groups. 21 patients included in the COVID-19 group and 32 patients in the control group. Symptom onset time was $7.1 \pm 3.1$ (min: 3, max: 14) days for COVID-19 patients. The most common symptom in the otolaryngology system was olfactory dysfunction $(\mathrm{n}=15,71.4 \%)$. The butanol olfactory threshold value was determined as an average of $4.4 \pm 1.9$ in the COVID-19 group and $6.4 \pm 0.8$ in the control group ( $p<0.001,95 \%$ CI $2.9-1.0)$. The sensitivity of the butanol threshold test for COVID-19 related olfactory dysfunction was $80.0 \%$ and the specificity was $66.6 \%$. For differential, early and initial, diagnosis of COVID-19,
\end{abstract}

Akif İşlek

drakifislek@gmail.com

1 Nusaybin State Hospital, Otolaryngology-Head \& Neck Surgery Clinic, Adar Street, 10/A-10, Nusaybin, Mardin, Turkey

2 Atatürk Training and Research Hospital, OtolaryngologyHead \& Neck Surgery Clinic, Katip Celebi University, İzmir, Turkey complaint of the smell dysfunctions, and impairment butanol threshold may be a distinctive indicator.

Keywords COVID-19 - CCCRC olfactory test . Hyposmia $\cdot$ Anosmia $\cdot$ Butanol threshold test

\section{Introduction}

Olfactory dysfunction after an upper respiratory tract infection associated with a common cold or influenza occurs between 11 and $40 \%$ [1]. Current studies have demonstrated that more than $20 \%$ of the population suffer from olfactory dysfunction [2]. Corona Viruses have been previously shown to cause olfactory dysfunction [3]. Olfactory and taste dysfunction up to a rate of $90 \%$ have been reported in the recent litearture with the COVID-19 pandemic [4, 5]. Brann et al. [6] demonstrate that subsets of olfactory epithelium co-express the CoV-2 receptor ACE2 and the spike protein protease TMPRSS2. Sun and Guan reported the first case of COVID-19 infection with positive findings in CSF and confirmed virus-associated neuroinvasion [7]. Most recently, the loss of smell and taste appears to be the most specific symptom for COVID-19, but there is no reported evidence with objective odor tests compared control group. This study aimed to show COVID-19-associated olfactory dysfunction with the butanol threshold test, which is an objective test and compared it with a healthy control group. 


\section{Method}

A cross-sectional study was designed. Between March 2020 and April 2020, symptomatic COVID-19 positive patients according to reverse-transcription polymerase chain reaction (RT-PCR) were included in the study at the second referral state hospital. The demographic characteristics of the patients were recorded. The onset of symptoms was determined. Head and neck system-specific and other symptoms were recorded. Only patients aged 18-65 years were included in the study. The odor identification test was not performed due to time constraints and the risk of transmission. Patients with a history of odor dysfunction and nasal surgery, allergic rhinitis, and sinus surgery were excluded from the study. Also, patients diagnosed with diabetes, neurological and psychiatric disorders were eliminated. In addition, healthy volunteers with no risk of COVID-19 transmission, with the same exclusion criteria, and no complaints of smell disorder were included in the control group.

Afterward, Connecticut Chemosensory Clinical Research Center (CCCRC) olfactory threshold test was performed according to the protocol in the literature. To shorten the test time, only the threshold test procedure was applied. For the butanol threshold test, two glass bottles were presented to the subject. One contained water and the other a dilute concentration of butanol. The most concentration of butanol was $4 \%$ butanol in deionized water. Each subsequent dilution (from highest concentration to lowest: total nine glass) was a 1:3 dilution with deionized water. Four consecutive correct answers were taken as the threshold. Possible scores ranged from 0 to 9 , but all scores 7 and higher were scored as 7 for each test [8]. The results of the butanol threshold test classified as normosmic: 6-7, hyposmic: $2-5$, and anosmic: $0-1$.

Threshold test values were compared with the MannWhitney U test between study groups. SPSS 22.0 program (IBM Corp., Armonk, NY, USA) was used for statistics. Verbal consent was obtained from all patients for the study. The study was carried out in accordance with the 1964 Helsinki Declaration and subsequent amendments. The institutional review board was approved by the local Provincial Health Directorate for the study (16/04/2020806.02.02).

\section{Results}

The study was carried out in 53 patients (COVID-19: 21, Control group: 32 ). The mean age was $49.2 \pm 13.5$ in all patients (min: 20, max: 65). The mean age and gender distribution in the study groups were similar (Table 1).
Symptom onset time was $7.1 \pm 3.1$ (min: 3 , max: 14) days before the threshold test for patients. The most common symptom in the otolaryngology system was olfactory dysfunction at the interview $(\mathrm{n}=15,71.4 \%)$ and the most common nonspecific symptom was cough $(\mathrm{n}=15$, 71.4.\%). In 5 (23.8\%) patients, odor dysfunction was not accompanied by taste dysfunction (Table 2). The butanol olfactory threshold test was determined as an average of $4.4 \pm 1.9$ in the COVID-19 group and an average of $6.4 \pm 0.8$ in the control group $(p<0.001,95 \% \mathrm{CI}$ 2.9-1.0), (Fig. 1), (Table 3).

According to the butanol threshold test, seven (33.3\%) patients were normosmic, $12(57.1 \%)$ were hyposmic, and two $(9.5 \%)$ were anosmic in the COVID-19 group. Three (9.4\%) patients determined as hyposmic and all others were normosmic in the control group. The sensitivity of the butanol threshold test for COVID-19 related olfactory dysfunction was $80.0 \%$ and the specificity was $66.6 \%$. In addition, the positive predictive value is $85.7 \%$ and the negative predictive value was $57.1 \%$. There was a significant correlation between the complaint of odor dysfunction and the threshold values $(p<0.001, \mathrm{r}=-0.661)$.

\section{Discussion}

The frequency of post viral odor disorder ranges from 18 to $45 \%[1,9,10]$. Sugiura et al. [11] mentioned the frequent association of coronaviruses with post-viral odor dysfunction earlier. During the pandemic, COVID-19 related olfactory dysfunctions reach up to $90 \%$ under definitions such as odor loss, smell disorder, odor dysfunctions, hyposmia, anosmia, sudden odor loss, however, objective findings reported are still insufficient. Thus, olfactory dysfunction stands out as a significant symptom in the early diagnosis of COVID-19. Early diagnosis and isolation are essential due to the high transmission rate of the SARSCoV-2 virus [12]. Wee et al. [13] reported that 22.7\% (35/ 154) of PCR positive patients have an odor and taste dysfunction at admission, and they calculated a high specificity as $98.7 \%$ versus lower sensitivity as $22.7 \%$. Lechien et al. [5] reported high rates of olfactory and gustatory dysfunctions as respectively $85.6 \%$ and $88.0 \%$ and they found that the olfactory dysfunction occurred before the other symptoms in $11.8 \%$ of cases. The available information is usually based on self-reported patient history or interviews. In this study, a significant lower olfactory threshold performance was determined as an average of $4.4 \pm 1.9$ in the COVID-19 patients on average $7.1 \pm 3.1$ days after symptom onset $(p<0.001$, CI 2.9-1.0). In addition, although there was no reported olfactory dysfunction in $2(9.5 \%)$ patients, they detected as hyposmic according to the butanol threshold test. In 
Table 1 Age and gender distribution of the participants according to the study groups with $p$-values

\begin{tabular}{|c|c|c|c|c|c|c|c|c|}
\hline & & Study & & & & & & \\
\hline & & Contr & & $\mathrm{COV}$ & & Tota & & $p$ \\
\hline Age $(\mathrm{m} \pm \mathrm{SD})$ & & 48.2 & 12.4 & 50.7 & 15.2 & 49.2 & 13.5 & $0.515^{*}$ \\
\hline Gender $(\mathrm{n}, \%)$ & Male & 18 & 56.3 & 12 & 57.1 & 30 & 56.6 & $0.949^{+}$ \\
\hline & Female & 14 & 43.8 & 9 & 42.9 & 23 & 43.4 & \\
\hline
\end{tabular}

$\mathrm{m} \pm \mathrm{SD}$, mean \pm Standard deviation

*Mann-Whitney U test, ${ }^{+}$Chi-Squared test

Table 2 Distribution of symptoms in COVID-19 patients

\begin{tabular}{llr}
\hline & $\mathrm{n}=21$ & $\%$ \\
\hline Odor dysfunction & 15 & 71.4 \\
Taste dysfunction & 10 & 47.6 \\
Sore throat & 8 & 38.1 \\
Nasal Obstruction & 2 & 9.5 \\
Nasal discharge & 4 & 19.0 \\
Sneeze & 1 & 4.8 \\
Dizziness & 3 & 14.3 \\
Headache & 5 & 23.8 \\
Fever & 12 & 57.1 \\
Cough & 15 & 71.4 \\
Dyspnea & 12 & 57.1 \\
Sputum & 6 & 28.6 \\
Fatigue & 8 & 38.1 \\
\hline
\end{tabular}

Fig. 1 Boxplot of threshold values by groups accordance with the literature, the rate of olfactory dysfunction in patients was $71.4 \%$.

CCCRC olfactory test is cost-effective, simple and practical and it was applicable for the Turkish population and has been proven validity and reliability [14]. The mean butanol threshold score was calculated as $6.36 \pm 0.7$ (range, 3.00-7.00) in the healthy participants for the Turkish population according to CCCRC olfactory test (14). In this study, according to butanol threshold test, $71.4 \%$ of patients (mean threshold: $4.4 \pm 1.9$ ) with COVID-19 had an odor disorder, and it was fairly lower than the normal population average calculated by Veyseller et al. [14]. Also, in this study, the mean threshold values in the control group were detected as $6.4 \pm 0.7$, and the average coincides with the reference study. In patients reporting olfactory dysfunction, the average of threshold values was $3.7 \pm 0.9$ and was lower than the control group, all of the COVID-19 patients, and the reported population

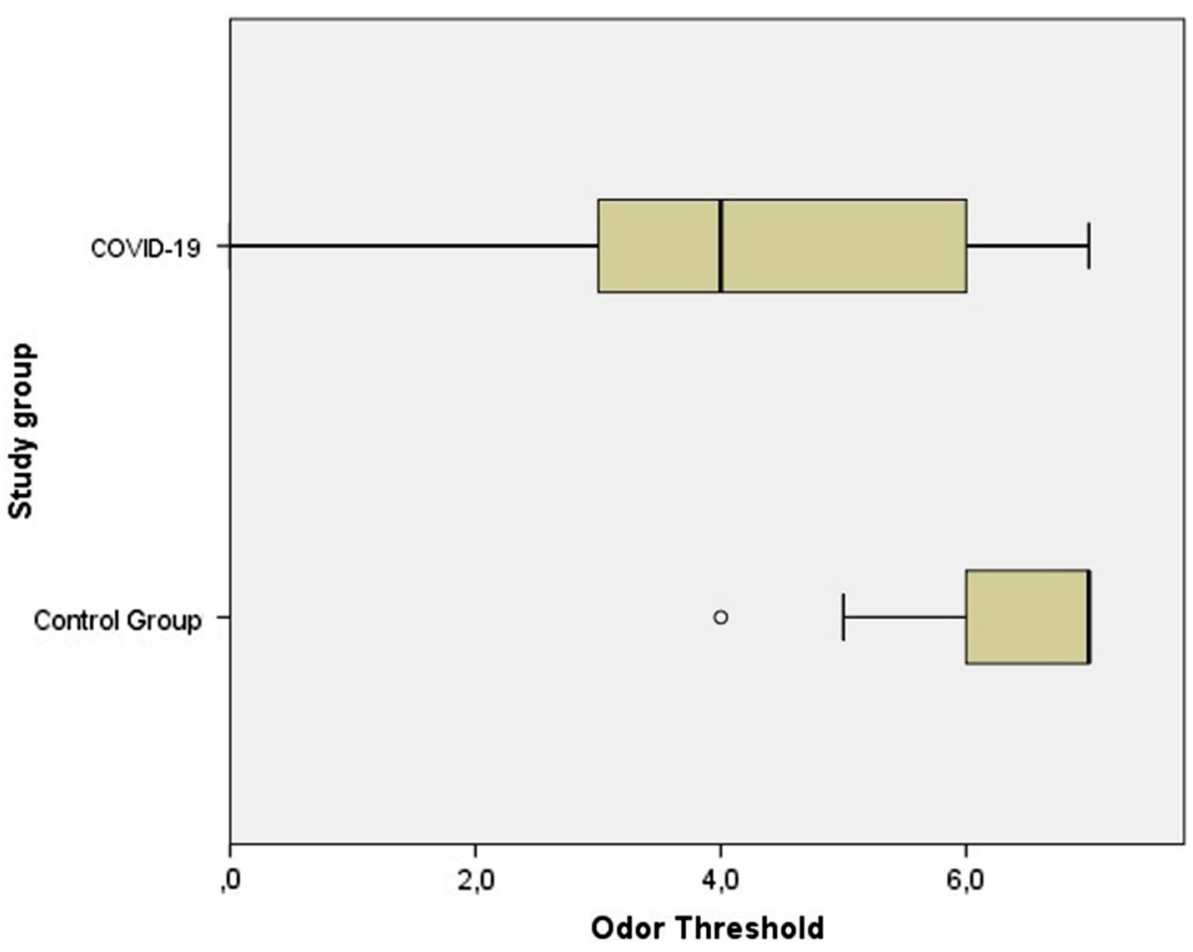


Table 3 Average of butanol threshold according to groups and $t$ test statistics

\begin{tabular}{|c|c|c|c|c|c|c|c|c|}
\hline & & \multicolumn{5}{|c|}{ Odor Threshold } & \multicolumn{2}{|l|}{$95 \% \mathrm{CI}$} \\
\hline & & $\mathrm{m}$ & SD & Min & Max & $p$ & Lower & Upper \\
\hline \multirow[t]{2}{*}{ Groups } & Control Group & 6.4 & .8 & 4.0 & 7.0 & $<0.001$ & -2.94 & -1.07 \\
\hline & COVID-19 & 4.4 & 1.9 & .0 & 7.0 & & & \\
\hline
\end{tabular}

m, mean; SD, Standard deviation

average. However, in the presented study, odor dysfunction was detected in $14(66.6 \%)$ of COVID-19 patients with the odor threshold test. A positive predictive value of $85.7 \%$ detected in this study for the butanol olfactory threshold test seems sufficient. Also, 2 (9.5\%) patients detected as hyposmic according to the threshold test results with no complaint of odor function (symptom onset: 2 and 4 days). The average incubation period of the COVID-19 after the transmission was detected 3-24 days according to cohort studies [15]. The butanol threshold test is a non-invasive, rapid, and objective method to determine the olfactory function and may recommend instead of the full protocol of the CCCR test in order to reduce the risk of transmission or transmission of the disease. However, according to data obtained from this study and current literature, monitorization of the odor function by patients with high COVID19 transmission risk seems a satisfactory method for early diagnosis of the disease. Consistent with the findings presented in this study, Moein et al. [16] demonstrated decreased olfactory dysfunction with a quantitative smell test (The University of Pennsylvania Smell Identification Test) and they supported the smell test may help to identify COVID-19 patients in need of early treatment or quarantine.

Mizumoto et al. [17] reported that estimated asymptomatic proportion is $17.9 \%$ (95\% CrI: $15.5-20.2 \%$ ), according to statistical modelling from 3711 people underwent a 2 -week quarantine. Similarly, the asymptomatic ratio was been estimated at $30.8 \%$ (95\% CrI $7.7-53.8 \%$ ) in an other study [18]. The butanol threshold test offers an objective measurement for olfactory functions. It can be an indicator test method for asymptomatic transmission or the patient had a long incubation period. Because it was reported that the sensitivity of negative PCR results could decrease to a rate of $40 \%$ related to sampling time [19]. Therefore, an impaired butanol threshold test may be a suitable indicator for early diagnosis of the patients who may be asymptomatic or whose symptoms have not yet appeared. The butanol threshold test objectively demonstrates odor dysfunction in COVID19 patients. However, performing a threshold test during the asymptomatic period or when symptoms are denied or unrecognized can be more significant for early diagnosis.
All patients enrolled in this study were symptomatic for COVID-19. If a similar study is conducted with larger samples and study groups including asymptomatic patients, it may give more significant and valid results. In addition, more detailed information can be obtained from a threshold test with an odor identification test.

\section{Conclusion}

Olfactory disorder rates are more common in COVID-19 patients than post-viral upper respiratory tract infections reported in the literature. High rates of initial odor dysfunctions may be a warning and specific symptom for COVID-19 disease and showed in this study objectively. For differential, early and initial, diagnosis of COVID-19, complaint of the smell dysfunctions, and impairment butanol threshold may be a distinctive indicator.

Author Contributions All authors contributed equally to the design of study, data collection, writing, review of the references, critical review, and final approved version of the manuscript.

Funding This research did not receive any specific grant from funding agencies in the public, commercial, or not-for-profit sectors.

Availability of Data and Materials Available.

\section{Compliance with Ethical Standards}

Conflict of interest The authors declare no conflict of interest.

Ethics Approval and Consent to Participate Ethics committee approval was obtained before the study. (80602-16/04/2020). Verbal and written consent was obtained after all participants were informed.

Consent for Publication The authors transfer all copyrights for the article to be published in this journal.

\section{References}

1. Welge-Lüssen A, Wolfensberger M (2006) Olfactory disorders following upper respiratory tract infections. Adv Otorhinolaryngol 63:125-132 
2. Miwa T, Ikeda K, Ishibashi T, Kobayashi M, Kondo K, Matsuwaki Y et al (2019) Clinical practice guidelines for the management of olfactory dysfunction-secondary publication. Auris Nasus Larynx 46:653-662. https://doi.org/10.1016/j.anl.2019. 04.002

3. Suzuki M, Saito K, Min WP, Vladau C, Toida K, Itoh $\mathrm{H}$ et al (2007) Identification of viruses in patients with postviral olfactory dysfunction. Laryngoscope 117:272-277

4. Giacomelli A, Pezzati L, Conti F, Bernacchia D, Siano M, Oreni L et al (2020) Self-reported olfactory and taste disorders in SARS-CoV-2 patients: a cross-sectional study. Clin Infect Dis 71:889-890

5. Lechien JR, Chiesa-Estomba CM, De Siati DR, Horoi M, Le Bon SD, Rodriguez A et al (2020) Olfactory and gustatory dysfunctions as a clinical presentation of mild-to-moderate forms of the coronavirus disease (COVID-19): a multicenter European study. Eur Arch Otorhinolaryngol 277(8):2251-2261. https://doi.org/10.1007/ s00405-020-05965-1

6. Brann DH, Tsukahara T, Weinreb C, Lipovsek M, Van den Berge K, Gong B, Chance R et al (2020) Non-neuronal expression of SARS-CoV-2 entry genes in the olfactory system suggests mechanisms underlying COVID-19-associated anosmia. Sci Adv 6(31):eabc5801. https://doi.org/10.1126/sciadv.abc5801

7. Sun T, Guan J (2020) Novel coronavirus and the central nervous system. Eur J Neurol. https://doi.org/10.1111/ene.14227 ([published online ahead of print, 2020 Mar 26])

8. Cain WS, Goodspeed RB, Gent JF, Leonasrd G (1988) Evaluation of olfactory dysfunction in the connecticut chemosensory clinical research center. Laryngoscope 98:83-88

9. Seiden AM (2004) Postviral olfactory loss. Otolaryngol Clin North Am 37:1159-1166

10. Cavazzana A, Larsson $M$, Münch $M$, Hähner A, Hummel $T$ (2018) Postinfectious olfactory loss: a retrospective study on 791 patients. Laryngoscope 128:10-15

11. Sugiura M, Aiba T, Mori J, Nakai Y (1998) An epidemiological study of postviral olfactory disorder. Acta Otolaryngol Suppl 538:191-196. https://doi.org/10.1080/00016489850182918
12. Yi Y, Lagniton PNP, Ye S, Li E, Xu R-H (2020) COVID-19: what has been learned and to be learned about the novel coronavirus disease. Int J Biol Sci 16(10):1753-1766

13. Wee LE, Chan YFZ, Teo NWY, Cherng BPZ, Thien SY, Wong HM et al (2020) The role of self-reported olfactory and gustatory dysfunction as a screening criterion for suspected COVID-19. Eur Arch Otorhinolaryngol 277:2389-2390. https://doi.org/10.1007/ s00405-020-05999-5

14. Veyseller B, Ozucer B, Karaaltin AB, Yildirim Y, Degirmenci N, Aksoy F et al (2014) Connecticut (CCCRC) olfactory test: normative values in 426 healthy volunteers. Indian J Otolaryngol Head Neck Surg 66:31-34

15. Ge H, Wang X, Yuan X, Xiao G, Wang C, Deng T et al (2020) The epidemiology and clinical information about COVID-19. Eur J Clin Microbiol Infect Dis 39:1011-1019. https://doi.org/10.1007/ s10096-020-03874-z

16. Moein ST, Hashemian SMR, Mansourafshar B, Khorram-Tousi A, Tabarsi P, Doty RL (2020) Smell dysfunction: a biomarker for COVID-19. Int Forum Allergy Rhinol 10:944-950

17. Mizumoto K, Kagaya K, Zarebski A, Chowell G (2020) Estimating the asymptomatic proportion of coronavirus disease 2019 (COVID-19) cases on board the Diamond Princess cruise ship, Yokohama, Japan, 2020. Euro Surveill 25:2000180. https://doi.org/ 10.2807/1560-7917.ES.2020.25.10.2000180

18. Nishiura H, Kobayashi T, Miyama T, Suzuki A, Jung SM, Hayashi $\mathrm{K}$ et al (2020) Estimation of the asymptomatic ratio of novel coronavirus infections (COVID-19). Int J Infect Dis 94:154-155. https://doi.org/10.1016/j.ijid.2020.03.020

19. Younes N, Al-Sadeq DW, Al-Jighefee H, Younes S, Al-Jamal O, Daas HI et al (2020) Challenges in laboratory diagnosis of the novel coronavirus SARS-CoV-2. Viruses 12:582. https://doi.org/ $10.3390 / \mathrm{v} 12060582$

Publisher's Note Springer Nature remains neutral with regard to jurisdictional claims in published maps and institutional affiliations. 